\title{
Auxin pretreatment promotes regeneration of sugarcane (Saccharum spp. hybrids) midrib segment explants
}

\author{
G. Franklin · S. Arvinth $\cdot$ C. J. Sheeba $\cdot$ \\ M. Kanchana $\cdot$ N. Subramonian
}

Received: 10 November 2005 / Accepted: 20 August 2006/ Published online: 10 November 2006

(C) Springer Science+Business Media B.V. 2006

\begin{abstract}
We have developed a new, simple, quick and genotype-independent method for direct regeneration of sugarcane using novel midrib segment explants. Our protocol involves two steps: the pretreatment of starting material on MS (Murashige and Skoog (1962) Physiol Plant 15:473-497) medium containing $3.0 \mathrm{mg} / \mathrm{l}$ 2,4dichlorophenoxyacetic acid (2,4-D) for 8 days under continuous dark and subsequent transfer of the explants to MS medium augmented with $0.1 \mathrm{mg} / \mathrm{l}$ benzyladenine (BA) and $0.1 \mathrm{mg} / \mathrm{l}$ naphthaleneacetic acid (NAA) under light-dark conditions. On the regeneration medium, numerous globular structures appeared from the explants and subsequently differentiated into shoots. Regenerated shoots attained $2-5 \mathrm{~cm}$ height within 30 days of culture initiation and readily rooted on MS basal medium. Hardened plants were successfully established in the greenhouse. The regulation of sugarcane morphogenesis by auxin pretreatment is discussed.
\end{abstract}

G. Franklin $(\bowtie) \cdot$ C. J. Sheeba

Department of Biology, Universidade do Minho, Campus de Gualtar, 4710-057 Braga,

Portugal

e-mail: franklin.gregory@gmail.com

S. Arvinth · M. Kanchana - N. Subramonian Crop Improvement Division, Sugarcane Breeding Institute (ICAR), Coimbatore 641007 , India
Keywords Auxin pretreatment $\cdot$ Direct regeneration $\cdot$ Globular structures $\cdot$ Midrib segments $\cdot$ Sugarcane
Abbreviations
BA 6-Benzyladenine
2,4-D 2,4-Dichlorophenoxyacetic acid
MS Murashige \& Skoog
NAA Naphthaleneacetic acid
PGR Plant Growth Regulator

\section{Introduction}

Sugarcane (Saccharum spp. hybrids) is a crop with high economic significance as it accounts for more than $70 \%$ of the world's sugar production. Because of the extreme genetic variability in the seed population, sugarcane is traditionally propagated by vegetative cuttings. The ever increasing demands for the true-to-type and disease-free sugarcane seedlings are currently met by micropropagation. Seed-canes for commercial purpose are produced either via direct organogenesis (Burner and Grisham 1995) or indirect somatic embryogenesis (Liu 1993; Brisibe et al. 1994; Blanco et al. 1997) using apical meristem and immature leaf callus, respectively as explants. In the direct shoot multiplication method, low frequency of plant regeneration is the potential 
limitation. Even though, embryogenesis is efficient and reproducible, it remains laborious and time-consuming. In somatic embryogenesis pathway, embryogenic callus obtained after repeated subculture of explant/primary callus on medium containing 2,4-D has been transferred to basal medium or medium with low auxin concentration for regeneration (Ahloowalia and Maretzki 1983). Repeated subculture and lengthy maintenance of callus on medium with 2,4-D might increase the probability of somaclonal variation. Moreover, as observed in monocots frequently (Mikami and Kinoshita 1988; Ma et al. 1987; Tomes and Smith 1985; Ogawa et al. 1999; Cardona and Duncan 1997; Chaudhury and Qu 2000; Hagio 2002), sugarcane tissue culture is also genotype-dependent (Burner 1992; Gill et al. 2004, 2006; Gandonou et al. 2005; Tiel et al. 2006).

Hence, establishment of robust protocols for direct regeneration has been the recent focus in sugarcane biotechnology and many studies attributed to this issue can be pointed out (Lakshmanan et al. 2005). Plant regeneration via direct somatic embryogenesis has been achieved from immature leaf thin cell layers (Lakshmanan et al. 2002). More recently, efficient direct somatic embryogenesis has been demonstrated from immature inflorescence (Desai et al. 2004) and thin cell layers possessing preemergent inflorescence (Snyman et al. 2006). Since sugarcane flowering is highly season-specific (Premachandran 1999), routine use of immature inflorescence materials in sugarcane biotechnology further needs the sophistication of artificial flowering induction (Snyman et al. 2006). Consistently available alternative explant with high regeneration potential is desirable, especially, when attempting for commercial scale micropropagation and routine transformation. Even though thin cell layers of immature sugarcane leaves were used as explants, midrib segments has been demonstrated as a potential explant in the present study for the first time.

Pretreatment of the plant material with plant growth regulators have increased regeneration rate in several plant species (Burnett et al. 1994; Yancheva et al. 2003). In rice, 2,4-D pretreatment of explants enhanced plant regeneration (Nhut et al. 2000). According to Chen et al. (2001), auxin regulates both division and expansion of plant cells mediated by a putative auxin binding protein ABP1. These reports prompted us to study the effect of 2,4-D pretreatment on regeneration of sugarcane.

\section{Materials and methods}

Media and culture conditions

MS medium (Murashige and Skoog 1962) containing a combination of $3 \%(\mathrm{w} / \mathrm{v})$ sucrose and $0.8 \%(\mathrm{w} / \mathrm{v})$ bacto agar (Himedia, Mumbai, India) was suitably supplemented with plant growth regulators (PGRs) as per requirement. The $\mathrm{pH}$ of the media was adjusted to 5.8 with $1 \mathrm{M} \mathrm{NaOH}$ or $1 \mathrm{M} \mathrm{HCl}$ before autoclaving. All cultures were incubated in light and dark (16 and $8 \mathrm{~h}$ ) conditions of cool-white-fluorescent light providing a quantum flux density of $30 \mu \mathrm{mol} \mathrm{s} \mathrm{m}^{-1}$ at $25 \pm 2{ }^{\circ} \mathrm{C}$ unless otherwise mentioned. Each culture plate containing $25 \mathrm{ml}$ medium was inoculated with 10-15 explants.

\section{Plant material}

Healthy shoots (main shoots or offshoots) with intact apical meristem and young leaves were collected from the field-grown sugarcane plants. Cylinders of young leaf rolls $(5-8 \mathrm{~cm}$ height) were cut-removed just above the shoot tip. These cylinders were treated with $0.5 \%$ fungicide (Bavistin, BASF, India) for $1 \mathrm{~h}$ and surface-sterilized with $0.1 \%$ (w/v) mercuric chloride for $3 \mathrm{~min}$. After each treatment, they were washed thoroughly in sterilized distilled water. Subsequently, the outer leaves/sheaths were pealed one by one until the cylinder reached approximately $0.5 \mathrm{~cm}$ in diameter. Then, the cylinders were either chopped transversely into thin slices $(0.5-1.0 \mathrm{~mm}$ thick) or made as $2.0 \mathrm{~cm}$ long midrib segments by removing the leaf blade and used as starting materials. Various parts of a sugarcane leaf are illustrated in Fig. 1A (Miller and Lentini 2004) and the appearance of midrib in transverse section of leaf is shown in Fig. 1B. 
Fig. 1 (A) Diagrammatic presentation of a sugarcane leaf showing different parts (adapted from Miller and Lentini 2004). (B) Transverse section of a typical sugarcane leaf showing leaf blade and midrib
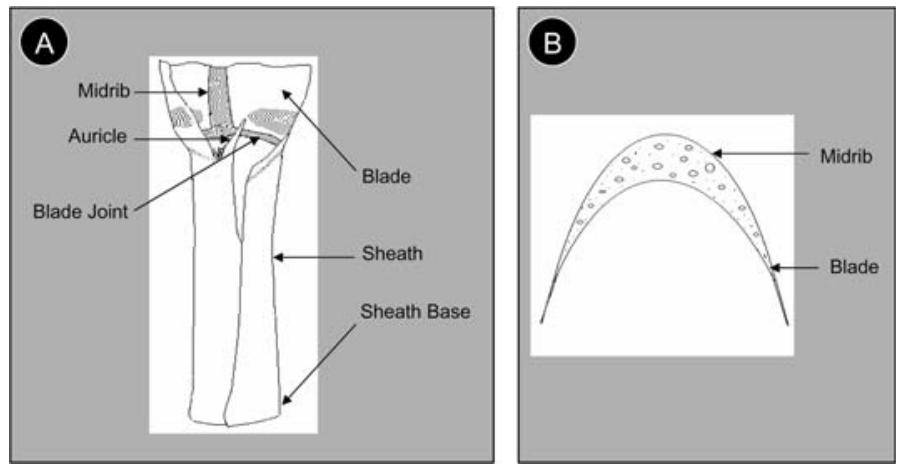

Optimization of 2,4-D pretreatment period

Starting materials (obtained from cv. CoC671) were cultured on MS medium containing $3.0 \mathrm{mg} / \mathrm{l}$ 2,4-D under continuous dark. Midrib segments (obtained from round transverse slices and sections taken from the $2.0 \mathrm{~cm}$ long midrib segments) were transferred to regeneration medium (optimized from regeneration experiments; $0.1 \mathrm{mg} / \mathrm{l} \mathrm{BA}$ and NAA $0.1 \mathrm{mg} / \mathrm{l}$ ) on days $0,5,8$ and 10 and cultured under light-dark (16-8 h) conditions. The pretreatment period which exhibited the best regeneration was considered optimum.

Optimization of plant regeneration from 2,4-D treated explants

To optimize efficient plant regeneration, midrib segments were transferred to MS medium supplemented with different concentrations of BA $(0.1-5.0 \mathrm{mg} / \mathrm{l})$ either alone or along with $0.1 \mathrm{mg} / \mathrm{l}$ NAA on the 8th day (optimized in the previous experiment) of 2,4-D pretreatment. Simultaneously, leaf blade segments (remaining portion of round transverse slices after removing midrib segments) were also tested for their regeneration potential as mentioned above. Elongated shoots $(2-5 \mathrm{~cm})$ were excised from the explant and transferred to baby food jars (Sigma, USA) containing MS basal medium for rooting. Culture jars with rooted plants were filled with sterilized distilled water and incubated at room temperature for hardening. After 3 days, the plants were carefully uprooted from the agar medium and thoroughly washed in running tap water to remove the traces of medium. Plantlets were implanted in plastic pots containing sterilized soil and compost (1:1) and irrigated with tap water regularly.

Histological observations of regeneration pathway

Cultured explants at different stages were fixed in FAA (formaldehyde: acetic acid: alcohol, 2:1:10) for 1 week. Following dehydration in tertiary butyl alcohol, the materials were infiltrated and embedded in paraffin wax $\left(t^{\mathrm{m}} 56-58^{\circ} \mathrm{C}\right)$ in a hot air oven at $59^{\circ} \mathrm{C}$. Sections were cut at $15 \mu \mathrm{m}$ thickness using microtome (Leica, India) and attached to glass slides using Haupt's solution. The slides were rinsed with xylene to remove wax and stained with $1 \%$ safranin. After removing excess stain, they were mounted in DPX solution (BDH chemicals, India), viewed and photographed under light microscope (Leica, India).

Statistical analyses of data

All the data were analyzed by Kruskal-Wallis test (one way ANOVA) followed by Dunn's multiple comparison test using GraphPad Prism version 4.00 for Windows (GraphPad Software, San Diego, California, USA).

\section{Results}

Duration of 2,4-D pretreatment influenced regeneration

To test the possibility that auxin pretreatment can enhance shoot regeneration in sugarcane, we 
studied the effect of 2,4-D for various time intervals. Both the starting materials increased in size considerably within a week's time. Midrib segments obtained from these pretreated materials turned green within a week and started producing shoots when transferred to regeneration medium and incubated under light-dark conditions. There was no difference in the regeneration response between midrib segment explants sectioned before (obtained from round transverse slices) and after (sections from the $2.0 \mathrm{~cm}$ long midrib segments) pretreatment. However, the regeneration response was strongly affected by the period of pretreatment. Percentage of explants showing plant regeneration gradually increased with pretreatment period until day 8 and thereafter declined (Table 1) and formed callus. Continuous culture of the explants on the pretreatment medium resulted in the formation of embryogenic callus (Fig. 2F). Control explants without pretreatment exhibited very low regeneration $(5 \%)$.

\section{BA favored plant regeneration}

from the pretreated explants

Plant regeneration from the pretreated midrib segments was critically affected by the BA concentration in a dose-dependent manner. Positive relationship could be established between the percentage of plant regeneration and BA concentration until $2.0 \mathrm{mg} / \mathrm{l}$ (Table 2). Addition of NAA $(0.1 \mathrm{mg} / \mathrm{l})$ along with BA further elevated the percentage of regeneration giving an optimum concentration of $0.1 \mathrm{mg} / \mathrm{l} \mathrm{BA}$ and $0.1 \mathrm{mg} / \mathrm{l}$ NAA. Medium without PGR supplementation or supplemented only with NAA did not show plant regeneration. Within 10 days of their transfer to media supplemented with BA, pretreated explants produced numerous globular structures from the dorsal and ventral surface (Fig. 2A). Neither callus nor globules were formed from the cut edges of midrib segments (Fig. 2A, arrow). On the other hand, similar globular structures were noticed in pretreated leaf blade segments from all over the surface including cut ends (Fig. 2C). These globules further differentiated into shoot buds within a week (Fig. 2B) and gave rise to shoots without subculture from both midrib (Fig. 2D) and leaf blade (Fig. 2E) segments. Subculture of explants with shoots to their respective media showed shoot multiplication in the range of 2-9 folds (9-24 shoots per midrib segment). The highest shoot multiplication rate (9-fold within 45 days) was achieved on medium augmented with $1.0 \mathrm{mg} / \mathrm{l} \mathrm{BA}$ and $0.1 \mathrm{mg} / \mathrm{l} \mathrm{NAA}$ (Table 2).

Pathway of plant regeneration is direct organogenesis

To understand the role of 2,4-D pretreatment in the regeneration process, we examined the pathway of plant regeneration by histological sections of explants fixed at different stages of regeneration. Globular structures containing cells with dense cytoplasm/nucleus prevailed in sections taken from explants cultured on regeneration medium for 10 days (Fig. 3A). These globular structures were not surrounded by callus and displayed typical characteristic features of a globular stage embryo; a well-defined globular shape without vascular connection to the original tissue. Development of shoot apex and primordial leaves from the globular structures were seen in sections of explants cultured for 20 days on regeneration medium

Table 1 Influence of pretreatment period with 2,4-D on regeneration of midrib segments cv. CoC671

\begin{tabular}{|c|c|c|c|c|}
\hline \multirow[t]{2}{*}{$\begin{array}{l}\text { Pretreatment period } \\
\text { with } 2,4-\mathrm{D} \text { (days) }\end{array}$} & \multirow[t]{2}{*}{$\begin{array}{l}\text { Midrib segments } \\
\text { regenerating (\%) }\end{array}$} & \multicolumn{3}{|c|}{$\begin{array}{l}\text { Mean no. shoots } \pm \text { SD per explant after various culture } \\
\text { intervals }\end{array}$} \\
\hline & & 18 days & 35 days & 45 days \\
\hline 0 & 5 & $2.0 \pm 0.3 a$ & $6.0 \pm 1.2 \mathrm{a}$ & $9.0 \pm 2.3 \mathrm{a}$ \\
\hline 5 & 30 & $2.8 \pm 0.5 a$ & $6.5 \pm 1.6 a b$ & $11.0 \pm 2.8 \mathrm{ab}$ \\
\hline 8 & 90 & $4.6 \pm 1.2 b$ & $10.9 \pm 2.8 b$ & $16.3 \pm 3.3 b$ \\
\hline 10 & 15 & $2.3 \pm 0.5 a$ & $5.5 \pm 1.5 \mathrm{a}$ & $7.8 \pm 2.9 \mathrm{a}$ \\
\hline
\end{tabular}

Values (Mean $\pm \mathrm{SD})$ in a column followed by the same letter are not significantly different $(P>0.05), n=20$ 

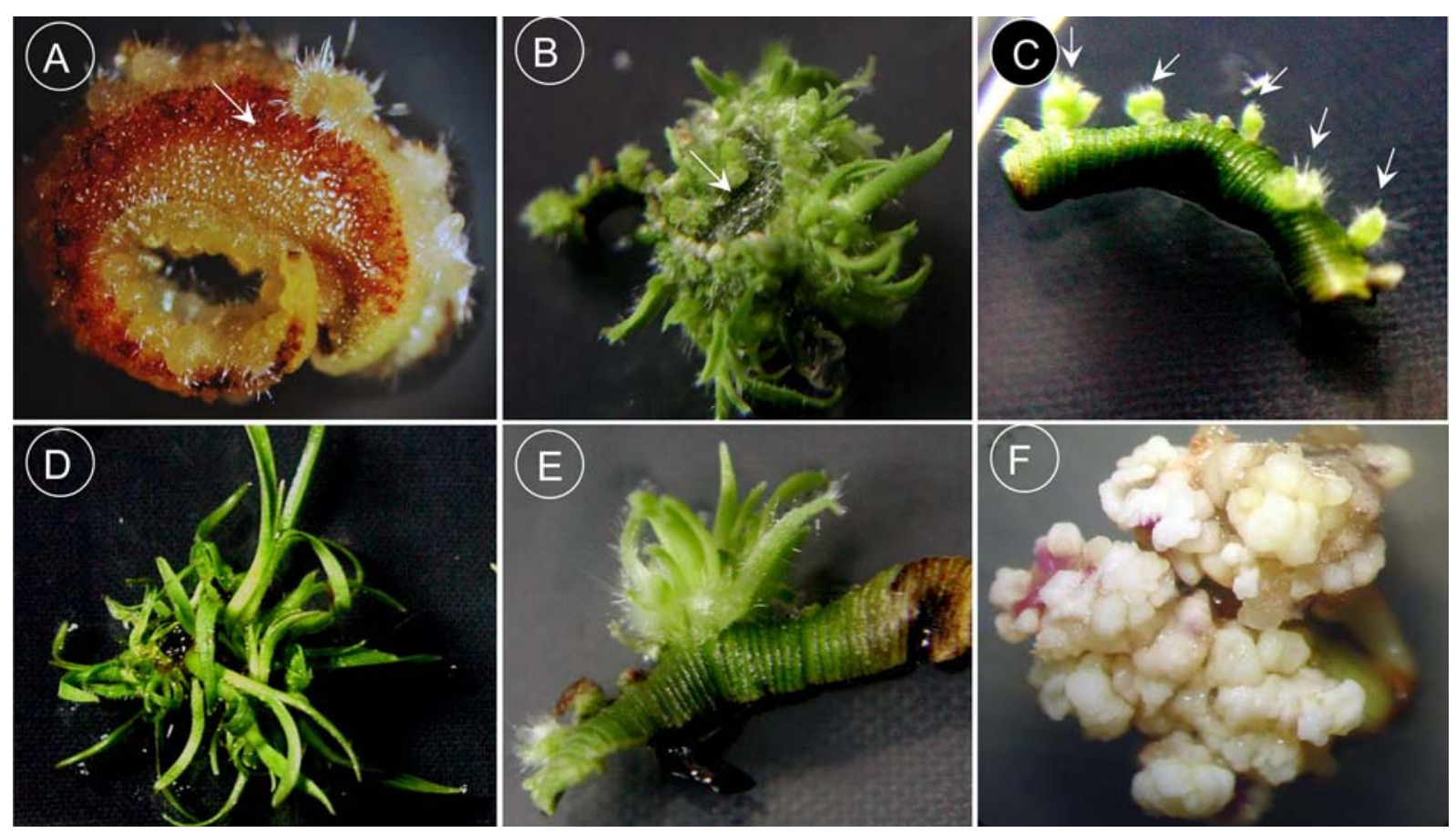

Fig. 2 Direct regeneration of sugarcane plants cv. CoC671. (A) Regeneration of shoots from midrib segments after 10 days on regeneration medium; (arrow shows the non-responsive portion of the explant with phenolic exudation), (B) Regeneration of shoots from midrib segments after 18 days on regeneration medium (arrow shows the non-responsive portion of the explant),

(C) Regeneration of shoots from leaf segments after 18 days on regeneration medium; (arrow shows the regenerating shoot buds), (D) Midrib with elongated shoots after 35 days on regeneration medium, (E) A leaf blade segment with a bunch of shoots after 25 days on regeneration medium, (F) Midrib segment continuously cultured on induction medium with embryogenic callus

Table 2 Regeneration of shoots from midrib segments pretreated for 8 days on medium supplemented with 3.0 mg/l 2,4-D on various PGR combinations cv. CoC671

\begin{tabular}{|c|c|c|c|c|c|}
\hline \multicolumn{2}{|c|}{ PGR (mg/l) } & \multirow[t]{2}{*}{$\begin{array}{l}\text { Midrib segments } \\
\text { regenerating }(\%)\end{array}$} & \multicolumn{3}{|c|}{$\begin{array}{l}\text { Mean no. shoots } \pm \text { SD per explant after various culture } \\
\text { intervals }\end{array}$} \\
\hline BA & NAA & & 18 days & 35 days & 45 days \\
\hline 0.0 & 0.0 & 0 & 0 & 0 & 0 \\
\hline 0.1 & 0.0 & 10 & $3.5 \pm 0.5 b$ & $19.0 \pm 4.3 \mathrm{e}$ & $22.5 \pm 3.6 \mathrm{~d}$ \\
\hline 0.5 & 0.0 & 20 & $1.4 \pm 0.3 \mathrm{a}$ & $5.3 \pm 1.8 \mathrm{abc}$ & $7.8 \pm 1.5 b$ \\
\hline 1.0 & 0.0 & 40 & $1.8 \pm 0.3 \mathrm{a}$ & $5.3 \pm 1.5 \mathrm{abc}$ & $8.0 \pm 1.8 b$ \\
\hline 2.0 & 0.0 & 80 & $1.8 \pm 0.3 \mathrm{a}$ & $3.5 \pm 1.6 \mathrm{ab}$ & $4.0 \pm 1.2 \mathrm{a}$ \\
\hline 5.0 & 0.0 & 0 & 0 & 0 & 0 \\
\hline 0.0 & 0.1 & 0 & 0 & 0 & 0 \\
\hline 0.1 & 0.1 & 90 & $4.6 \pm 1.2 b$ & $10.9 \pm 2.8 \mathrm{~d}$ & $16.3 \pm 3.3 \mathrm{~cd}$ \\
\hline 0.5 & 0.1 & 80 & $1.3 \pm 0.3 \mathrm{a}$ & $5.9 \pm 0.8 \mathrm{bc}$ & $8.3 \pm 1.9 b$ \\
\hline 1.0 & 0.1 & 50 & $4.0 \pm 1.0 \mathrm{~b}$ & $31.0 \pm 6.3 \mathrm{f}$ & $37.0 \pm 7.4 \mathrm{e}$ \\
\hline 2.0 & 0.1 & 90 & $1.4 \pm 0.3 \mathrm{a}$ & $7.0 \pm 1.6 \mathrm{~cd}$ & $7.5 \pm 1.8 b$ \\
\hline 5.0 & 0.1 & 20 & $1.5 \pm 0.5 \mathrm{a}$ & $4.0 \pm 0.8 \mathrm{a}$ & $4.0 \pm 1.3 \mathrm{a}$ \\
\hline
\end{tabular}

Values (Mean \pm SD) in a column followed by the same letter are not significantly different $(P>0.05), n=20$ 
Fig. 3 Histological observations of explants at different stages of regeneration. (A) Section of midrib explant after 10 days on regeneration medium showing globular structure (arrow) made up of meristematic cells (bar $=50 \mu \mathrm{m}, 153 \times$ magnification), (B) Development of shoot apex and primordial leaves (arrow) from a globular structure (bar $=50 \mu \mathrm{m}, 147 \times$ magnification), (C) Section of midrib explant after continuous culture on induction medium showing different stages of somatic embryos (arrow) made up of meristematic cells (bar $=50 \mu \mathrm{m}, 153 \times$ magnification)

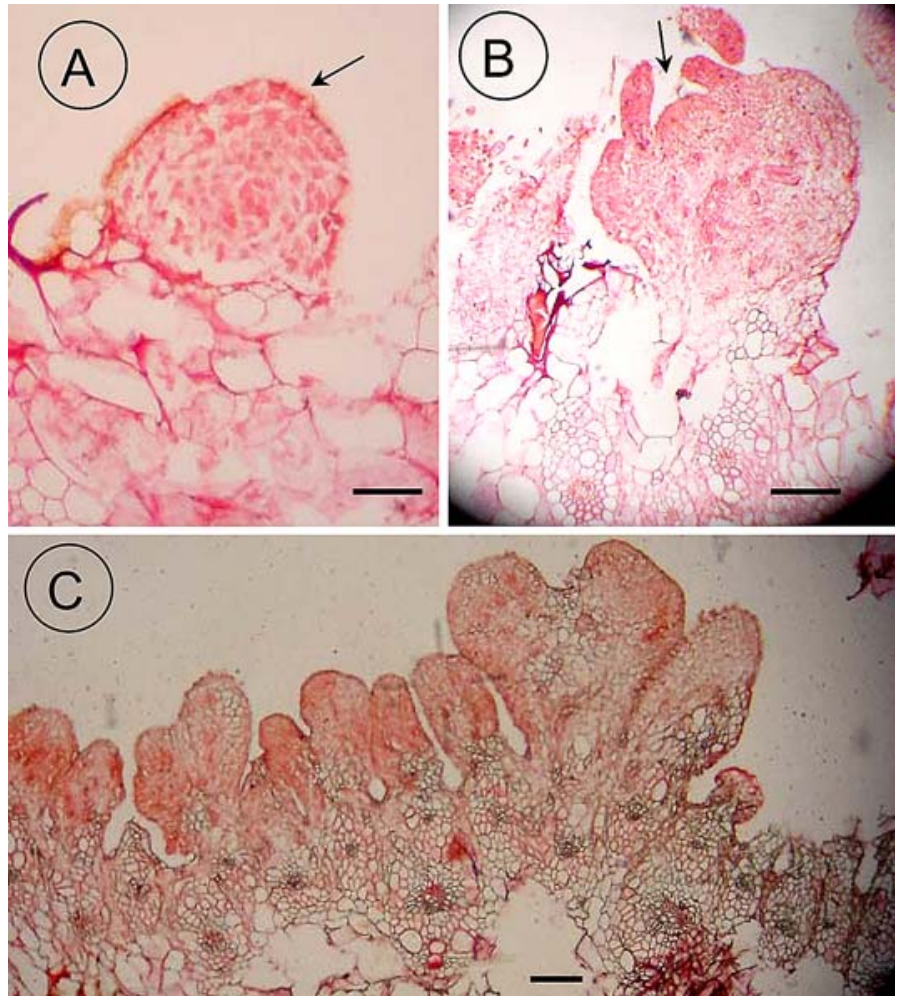

(Fig. 3B). In contrast, defined embryogenic stages were seen in explants cultured continuously on medium augmented with 2,4-D (Fig 3C).

Efficient plant regeneration from midrib segment explants is genotype-independent

To demonstrate the genotypic independency of the protocol, midrib segments of five more genotypes (Co86032, Co740, Co775, Co62175 and CoJ64) were tested under optimal conditions standardized for the variety CoC671. All of them produced globular structures and subsequently shoots as observed for CoC671. The percentage of midrib segments showing plant regeneration ranged between $80 \%$ and $100 \%$ among the genotypes (Table 3). These observations revealed that the pathway of plant regeneration and regeneration from midrib segments is genotype-independent.

\section{Discussion}

From the results of this study, it is clear that the period of pretreatment/induction with 2,4-D played an important role in plant regeneration. The gradual increase in the regeneration percentage with increasing period of induction shows that the number of morphogenetically potential cells had increased in a time-dependent manner during pretreatment. Since continuous culture of explants on auxin medium resulted in the formation of embryogenic callus, it is also clear that once the morphogenetic competency had been induced, auxin promotes embryogenesis and inhibits the development of shoots. Fitch and Moore (1990) reported that the explants resulted in continuous callus proliferation without regeneration when maintained on medium augmented with 2,4-D. The low regeneration potential of explants on medium containing BA without pretreatment suggests that BA did not have any role in the earlier phase of regeneration. After 10 days of auxin pretreatment, explants produced callus in high frequency on medium fortified with BA, indicating that they loose their amenability towards BA after the optimum period. Hence, for efficient direct regeneration, period of auxin treatment and the timing of BA application are crucial. 
Table 3 Regeneration of shoots from midrib segments of different genotypes pretreated for 8 days on medium supplemented with $3.0 \mathrm{mg} / 1$ 2,4-D

\begin{tabular}{lclrr}
\hline Genotype & $\begin{array}{l}\text { Midrib segments } \\
\text { regenerating }(\%)\end{array}$ & \multicolumn{3}{l}{ Mean no. shoots } \\
\cline { 3 - 5 } & & 18 days & SD per explant after various culture intervals \\
\hline CoC671 & 90 & $4.6 \pm 1.2 \mathrm{~b}$ & $10.9 \pm 2.8 \mathrm{~b}$ & 45 days \\
Co86032 & 100 & $6.3 \pm 1.8 \mathrm{~b}$ & $15.9 \pm 4.3 \mathrm{~b}$ & $16.3 \pm 3.3 \mathrm{bc}$ \\
CoJ64 & 100 & $4.7 \pm 1.6 \mathrm{~b}$ & $9.3 \pm 2.4 \mathrm{~b}$ & $23.8 \pm 4.5 \mathrm{c}$ \\
Co740 & 80 & $2.2 \pm 0.6 \mathrm{a}$ & $5.6 \pm 1.3 \mathrm{a}$ & $19.7 \pm 4.3 \mathrm{bc}$ \\
Co775 & 80 & $3.9 \pm 0.8 \mathrm{~b}$ & $10.5 \pm 2.3 \mathrm{~b}$ & $9.5 \pm 2.3 \mathrm{a}$ \\
Co62175 & 100 & $5.2 \pm 1.5 \mathrm{~b}$ & $9.6 \pm 2.1 \mathrm{~b}$ & $14.6 \pm 3.3 \mathrm{ab}$ \\
\hline
\end{tabular}

Values (Mean $\pm \mathrm{SD})$ in a column followed by the same letter are not significantly different $(P>0.05), n=20$

Induction of globular structures and their subsequent differentiation into adventitious shoots from the explants on media supplemented with BA suggests that the pathway of plant regeneration can be efficiently regulated by a cytokinin after auxin pretreatment. Histological observations of the explants at different stages of regeneration provided evidence for the conversion of globular structures (globular stage embryos) into shoots. In embryogenesis, the preembryogenic units should be converted into transition units which are polarized structures composed of tightly arranged meristematic cells at the apical pole and suspensor-like elongated cells at the basal pole within a short time (Samaj et al. 2003). Another distinctive feature of somatic embryos is the separation from the explant leading to the formation of a plantlet. Aforementioned structures were not found in any stages of the explant in the present study. On the other hand, numerous tiny shoots with well-developed leaves that were inseparable from the explants were appeared. All the above observations collectively suggest that the globular structures (globular embryos) can lead to shoot formation via organogenesis. In rice, Nhut et al. (2000) reported that more than $93 \%$ of thin cell layer explants pretreated with 2,4-D under dark for 2 weeks, formed embryo-like structures on day 7 in the presence of $1 \mu \mathrm{M}$ BAP and light. Subsequently, those structures differentiated directly into shoots without an intermediate callus phase.

The variation in the regeneration response between midrib and leaf blade segments could be the reflection of their sensitivity different tissues towards PGRs. It should be noted that midrib and leaf blade are two distinct tissue types and their development is controlled by unrelated genes (Yamaguchi et al. 2004). The inability to induce shoots from the cut ends of midrib segments is mainly due to the production of phenolic compounds. In this context, the close positive correlation previously demonstrated between sugarcane shoot formation and phenolic excretion is paradoxical (Lorenzo et al. 2001). In our preliminary transient expression studies with GUS gene, we did not see the gene expression after bombardment, when the cut regions of the midrib segments were targeted. On the other hand, when the dorsal or ventral surface of the midrib was targeted, GUS foci could be seen indicating that the phenolic production at the cut regions interferes with transformation process also (data not shown).

Since all the varieties produced globular structures and shoots on regeneration media, the pathway of plant regeneration is also common to all the tested genotypes. Difference in the morphogenetic potential of sugarcane cultivars has been frequently reported. Burner (1992) found a high degree of variation among caryopses of three varieties in callus production and plant regeneration. Cultivar specificities in somatic embryogenesis and direct organogenesis from leaf segments have been reported among Indian sugarcane cultivars (Gill et al. 2004, 2006). Gandonou et al. (2005) observed significant difference between genotypes in callus induction capacity, embryogenic response and plant regeneration. Spindle sections of two Cuban varieties (C1051-73 and C86-12) showed significant difference in their regeneration potential (Tiel et al. 2006). In the 
present study, efficient plant regeneration after 2,4-D treatment in all the tested varieties (CoC671, Co86032, Co740, Co775, Co62175 and CoJ64) suggests that this pretreatment played an important role in nullifying the genotypic effects.

In conclusion, we have demonstrated an efficient, genotype- independent direct plant regeneration method for sugarcane using auxin pretreatment. Induction of globules from midrib segments yielded a large number of shoots within a short period; an average of 23.75 shoots per midrib segment was recorded for the variety Co86032 on optimal regeneration medium. In addition, this protocol is highly repeatable and thus applicable for commercial micropropagation and genetic transformation of sugarcane. It seems that this method can be extended to other monocots to reduce the genotypic effects frequently reported during regeneration process.

\section{References}

Ahloowalia BS, Maretzki A (1983) Plant regeneration via somatic embryogenesis in sugarcane. Plant Cell Rep 2:21-25

Blanco MDA, Nieves N, Sanchez M, Borroto CG, Castillo R, Gonzalez JL, Escalona M, Baez E, Hernandez Z (1997) Protein changes associated with plant regeneration in embryogenic calli of sugarcane (Saccharum sp.). Plant Cell Tiss Org Cult 51:153-158

Brisibe EA, Miyake H, Taniguchi T, Maeda E (1994) Regeneration of somatic embryogenesis in long term callus cultures of sugarcane (Saccharum officinarum L). New Phytol 126:301-307

Burner MD (1992) Regeneration and phenotypic variability of plants cultured in vitro from mature sugarcane caryopses. J Am Soc Sugar Cane Technol (ASSCT), 12: Florida and Louisiana Divisions: 82-90

Burner MD, Grisham MP (1995) Induction and stability of phenotypic variation in sugarcane as affected by propagation procedure. Crop Sci 35:875-880

Burnett L, Arnoldo M, Yarrow S, Huang B (1994) Enhancement of shoot regeneration from cotyledon explants of Brassica napus ssp. oleifera through pretreatment with auxin and cytokinin and use of ethylene inhibitors. Plant Cell Tiss Org Cult 37:253-256

Cardona CA, Duncan RR (1997) Callus induction and high efficiency plant regeneration via somatic embryogenesis in Paspalum. Crop Sci 37:1297-1302

Chaudhury A, Qu R (2000) Somatic embryogenesis and plant regeneration of turf-type bermuda grass: Effect of 6-benzyladenine in callus induction medium. Plant Cell Tiss Org Cult 60:113-120
Chen JG, Shimomura S, Sitbon F, Sandberg G, Jones AM (2001) The role of auxin binding protein 1 in the expansion of tobacco leaf cells. Plant J 28:607-617

Desai NS, Suprasanna P, Bapat VAM (2004) Simple and reproducible protocol for direct somatic embryogenesis from cultured immature inflorescence segments of sugarcane. (Saccharum spp.). Curr Sci 87:764-768

Fitch MMM, Moore PH (1990) Comparison of 2,4-D and picloram for selection of long-term totipotent green callus cultures of sugarcane. Plant Cell Tiss Org Cult 20:157-163

Gandonou Ch, Errabii T, Abrini J, Idaomar M, Chibi F, Skali Senhaji N (2005) Effect of genotype on callus induction and plant regeneration from leaf explants of sugarcane (Saccharum sp.). Afr J Biotecnol 11:12501255

Gill NK, Gill R, Gosal SS (2004) Factors enhancing somatic embryogenesis and plant regeneration in sugarcane (Saccharum officinarum L.). Ind J Biotehnol 3:119-123

Gill R, Malhotra PK, Gosal SS (2006) Direct plant regeneration from cultured young leaf segments of sugarcane. Plant Cell Tiss Org Cult 84:227-231

Hagio T (2002) Adventitious shoot regeneration from immature embryos of Sorghum. Plant Cell Tiss Org Cult 68:65-72

Lakshmanan P, Geijskes RJ, Aitken KS, Grof CLP, Bonnett GD and Smith GR (2005) Sugarcane biotechnology: the challenges and opportunities. In Vitro Cell Dev Biol-Plant 41:345-363

Lakshmanan P, Geijskes RJ, Elliott AR, Wang LF, Mckeon MG, Swain RS, Borg Z, Berding N, Grof CPL, Smith GR (2002) A thin cell layer culture system for the rapid and high frequency direct regeneration of sugarcane and other monocot species. In: Vasil IK (ed) Proc X Int Assoc Plant Tiss Cult Biotechnol. Orlando, June 23-28

Liu MC (1993) Factors affecting induction, somatic embryogenesis and plant regeneration of callus from cultured immature inflorescence of sugarcane. J Plant Physiol 141:714-720

Lorenzo JC, Blanco MA, Pelaez O, Gonzalez A, Cid M, Iglesias A, Gonzalez B, Escalona M, Espinosa P, Borroto C (2001) Sugarcane micropropagation and phenolic excretion. Plant Cell Tiss Org Cult 65:1-8

Ma H, Gu M, Liang GH (1987) Plant regeneration from cultured immature embryos of Sorghum bicolor (L.). Theor Appl Genet 73:389-394

Mikami T, Kinoshita T (1988) Genotype effects on the callus formation from different explants of rice, Oryza sativa L. Plant Cell Tiss Org Cult 12:311-314

Miller JD, Lentini RS (2004) Sugarcane botany: a brief view. Florida sugarcane handbook. UF/IFAS, http:// edis.ifas.ufl.edu/images/113924850

Murashige T, Skoog F (1962) A revised medium for rapid growth and bioassays with tobacco tissue cultures. Physiol Plant 15:473-497

Nhut DT, Bui VL, Tran Thanh Van K (2000) Somatic embryogenesis and direct shoot regeneration of rice (Oryza sativa L.) using thin cell layer culture of apical meristem. J plant physiol 157:559-564 
Ogawa T, Fukuoka H, Yano H, Ohkawa Y (1999) Relationships between nitrite reductase activity and genotype-dependent callus growth in rice cell cultures. Plant Cell Rep 18:576-581

Premachandran MN (1999) Flowering behavior and pollen fertility of Indian hybrid varieties of sugarcane. Ann Agric Res 20:23-26

Samaj J, Baluska F, Pretova A, Volkmann D (2003) Auxin deprivation induces a developmental switch in maize somatic embryogenesis involving redistribution of microtubules and actin filaments from endoplasmic to cortical cytoskeletal arrays. Plant Cell Rep 21:940-945

Snyman SJ, Meyer GM, Richards JM, Haricharan N, Ramgareeb S, Huckett BI (2006) Refining the application of direct embryogenesis in sugarcane: effect of the developmental phase of leaf disc explants and the timing of DNA transfer on transformation efficiency. Plant Cell Rep DOI 10.1007/s00299-006-0148-z
Tiel K, Enriquez GA, Ceballo Y, Soto N, Fuentes AD, Ferreira A, Coll Y, Fuentes D (2006) Development of a system for rapid plant regeneration from in vitro sugarcane (Saccharum officinarum L.). Biotechnol Appl 23:22-24

Tomes DT, Smith OS (1985) The effect of parental genotype on initiation of embryogenic callus from elite maize (Zea mays L.) germplasm. Theor Appl Genet 70:505-509

Yamaguchi T, Nagasawa N, Kawasaki S, Matsuoka M, Nagato Y, Hirano HY (2004) The YABBY Gene DROOPING LEAF regulates carpel specification and midrib development in Oryza sativa. Plant Cell 16:500-509

Yancheva SD, Golubowicz S, Fisher E, Lev-Yadun S, Flaishman MA (2003) Auxin type and timing of application determine the activation of the developmental program during in vitro organogenesis in apple. Plant Sci 165:299-309 